\title{
Motor behavior as a scientific field: A view from the start of the $21^{\text {st }}$ Century
}

\author{
Jane E. Clark ${ }^{1,2}$ \& Marcio A. Oliveira ${ }^{1}$ \\ ${ }^{1}$ Department of Kinesiology \\ ${ }^{2}$ Program in Neuroscience and Cognitive Science \\ University of Maryland, College Park, MD 20742-2611
}

\begin{abstract}
At the start of the $21^{\text {st }}$ century, the study of motor behavior is a mature and vibrant scientific field. In this paper, we describe the development of this field by tracing the history of its sub-areas: motor control, motor learning, and motor development. Our understanding of how humans control and coordinate their multi-segmented body in an ever changing environment across the lifespan has grown and matured enormously over the last 100 years. Today, these three sub-areas are converging as our scientific questions build upon the foundations laid by scientists in each of these areas. We end our paper by considering the future in this field and the challenges facing motor behavior scientists in this new century.
\end{abstract}

Key Words: Motor development, motor learning, motor control.

\section{Preface}

The authors would like to thank Dr. Jose Barela for the invitation to contribute to this first issue of the Brazilian Journal of Motor Behavior. We are honored to be included and to offer our thoughts on the field of motor behavior at the start of the $21^{\text {st }}$ century. This was a daunting task. As the reader will find, motor behavior has an immense scientific literature and we have only captured a glimpse of this important field of study. Finally, we apologize in advance for our omissions and, in particular, our focus on motor behavior in the United States of America. The scope of a global review would be well beyond this paper, but we strongly encourage others to take up the task.

\section{Introduction}

The scientific study of motor behavior has a long history dating back to the Greek civilization (400 BC) when scholars without any of today's modern technology rightly attributed movements of the hand, mouth, and feet to the brain. In the centuries that follow, the study of motor behavior has developed into a significant area of scholarship that has not only confirmed the Greeks' suppositions, but has made amazing progress in understanding how humans learn and perform movements over their lifespan. For most, the actions of our daily lives go on without much notice. We rise from bed, eat our breakfast, dress, go to work, and perhaps play a sport. Rarely, do we consider how we perform these activities of our daily lives. Not until we watch a young infant or someone who has had a stroke struggle to achieve any one of our routine actions, do we pause to think how it is that we achieve our goals. How does the central nervous system and the musculoskeletal system come together to create the highly timed, spatially accurate behaviors that characterize much of adults' motor behavior? It is questions such as these that the field of motor behavior seeks to answer.

In the last century, the study of motor behavior can be found in three major scientific fields: psychology, physiology, and kinesiology (or, as it was called for most of the century in the US and continues to be called in Brazil: physical education). For example, early in the last century, psychology often used motor tasks to study human behavior (Woodworth, 1921). However, from the 1950s onward, psychology, neglected motor behavior as a legitimate area of study (Rosenbaum, 2005), although psychological theories and methods have had a significant impact on those in kinesiology studying motor behavior. That is, psychological concepts such as memory, attention, learning, skill, and knowledge of results are integral concepts in motor behavior research. Since the late 1800 s, motor behavior has been an important area of study in physiology. However, much of the research in physiology has been conducted on animals and only in the last several decades has there been a shift in physiology/neurophysiology to human motor behavior (Matthews, 2004). In 
contrast to psychology and physiology, motor behavior has been a central area of study in kinesiology (Thomas, 2006; Ulrich \& Reeve, 2005). This is, in large measure, due to the importance of motor skill learning and performance in physical education and sports.

Today, three distinct areas of motor behavior are recognized. These are: motor development, motor learning, and motor control. Motor learning has been defined as the study of how we learn motor skills as a result of practice or experience that leads to a relatively permanent change in behavior (Schmidt, 1982). Motor control is the study of the underlying mechanisms that enable movements to be organized and controlled. Motor development refers to the changes in motor behavior over the lifespan and the process(es) which underlie these changes (Clark \& Whitall, 1989). All three of these areas of motor behavior are well established with substantial literatures, methodologies, and programmatic research efforts (Thomas, 2006). However, the scientific traditions that have separated these areas have, in recent years, converged. In a recent review of the three fields, Ulrich and Reeve (2005) suggested that the field unify under the name of motor behavior so as to promote an "...understanding of the processes underlying motor performance across the lifespan" (p. S67). We agree with these authors and at the paper's end offer our own comments on a future name for the field.

Our purpose for the present paper is to elaborate on these three areas of study by describing their histories and in doing so, demonstrate the richness and scientific depth that characterizes the field of motor behavior. Like Ulrich and Reeve, we see the current state of the field of motor behavior not as three distinct areas of study, but as one area with significant scientific cross-clustering between the sub-areas. Indeed we will demonstrate through examples, how these areas have come together theoretically and pragmatically to address the important scientific issues in motor behavior today.

The paper is divided into three sections. The first part of the paper provides an historical overview of the three areas as well as the important contributions each has made to our present understanding of motor skills. In the second part, we provide our picture of the current status of the field and to show where we are today and what are the significant issues and questions pursued by researchers in the field. Finally, we consider the future research problems in the motor behavior and the challenges for new comers in the field as we begin the $21^{\text {st }}$ century.

\section{A brief historical overview of the motor behavior field}

Several in-depth historical reviews of the areas of motor behavior have been written (Adams, 1987; Clark \& Whitall, 1989; Thomas, 1997; 2006; Whitall, 1995). Our purpose here is not to repeat these reviews, but to highlight these histories as a foundation for where we are today and what we see as the future of the scientific study of motor behavior.

\section{Motor Control}

Those who study motor control focus their questions on what are the underlying processes or mechanisms that allow animals (including humans) to control and coordinate their movements. Motor behaviors can be observed and measured. But those in motor control seek to understand how the central nervous system and the muscles work together to achieve the observed control and coordination.

Motor control has a history intertwined with a broader discipline that in its early stages studied movement, but as it progressed as a scientific area would marginalize movement. The broader discipline for motor control was physiology or as it has come to be known: neurobiology/ neurophysiology. To describe the history of motor control we have divided it into four periods: 1) the foundation period $(1791 \quad$ - 1893); 2) the Sherrington period (1894 - 1929); 3) the building period (1930 - 1964); and the 4) neuroscience period (1965 - to present).

Notions about the brain and its role in motor behavior date back to the time of the Greeks. Centuries later, Descartes (1649) wrote that the sole cause of a muscle contraction was "animal spirits" from the brain. Descartes was wrong about "spirits," but it would take another hundred years before the start of the foundation period (1791 1900), when Galvani (1792) would show that it was not spirits that caused the muscles to contract, but rather electrical impulses. The connection of the muscles to the brain, however, would not be demonstrated for almost another century when Fritsch and Hitzig (1870) electrically stimulated the cortical surface in the precentral gyrus area of a dog and produced muscular contractions of the limbs on the opposite side of the body. Ferrier (1873) would extend on these studies showing that this area (later called the primary motor area) was the most excitable area of the brain for eliciting movements. There was indeed a motor area in the brain and the functions were lateralized. In 
addition, this work revealed the importance of the cerebral cortex in movement. Up to this time, it was commonly believed that the function of the cerebral cortex was for thinking only. Later Jackson's work on the motor disruptions associated with epileptic seizures provided the idea that there was hierarchical control of movement within the nervous system (Taylor, 1958). This important concept was referred to as the "chain of command." Commands for voluntary, goal-directed movements begin in the higher centers of the nervous system and are relayed to lower centers; that is, the spinal cord which controls automatic primitive movements. The notion of hierarchical control was to find support from work on the cerebellum which revealed the important role played by this neural structure in regulating muscle tone and coordinating movements (Flourens, 1824; Luciani, 1891). This work also indicated that the cerebellum was lower in the hierarchy and appeared to regulate or adjust the muscular system helping the cerebral cortex accomplish the movement that was planned.

A major question that confronted scientists during this early period was what was the basic anatomical unit of the nervous system? The concept that the nervous system was composed of discrete units or nerve cells was proposed late in the $19^{\text {th }}$ century, but it was not until the detailed and definitive experiments of Cajal in 1911 that it was finally resolved that the basic unit was the neuron (see for review of this history, Eccles, 1959).

At the start of the twentieth century, many fundamental concepts about neurophysiology that we understand today had not been resolved (Kevles \& Geison, 1995). The start of the Sherrington period (1894-1929) begins a productive and critical period in neurophysiology. We mark the beginning of this period just before the start of the $20^{\text {th }}$ century with the publication in 1894 of the classic paper on the muscle spindle (Sherrington, 1894). One of the earliest discoveries of Sherrington was that the muscle spindle was a sensory organ which informed the nervous system of the state of contraction of the skeletal muscle (Sherrington, 1894). Later, Sherrington expanded his discoveries with the introduction of the concept of proprioception (Sherrington, 1906). Proprioceptors (the muscle spindles, joint and tendon receptors and those of the labyrinthine), Sherrington posited, are the sensory receptors which monitor the body's movement.

As Sherrington worked to describe the anatomical and functional aspects of the nervous system, he came to realize that this was an integrated system of receptors, effectors and conductors. The integration of these into a unit of action was realized in the concept of the reflex (Sherrington, 1906). Importantly, and often overlooked, Sherrington noted that the simple reflex was probably purely an abstract concept that provided a "...convenient, if not a probable fiction" (Sherrington, 1906, p.7-8) for understanding the functioning of the nervous system. From this initial idea emerged other concepts such as the stretch reflex and the motor unit (Liddell \& Sherrington, 1925), the principle of the final common pathway (Sherrington, 1906), and reciprocal innervations (Sherrington, 1893; Sherrington, 1896).

Sherrington's focus on discrete behaviors such as the stretch reflex left him less able to conceptualize more complex behaviors including rhythmic behaviors such as those seen in locomotion. In 1914, Graham Brown challenged the notion that behavior was driven by a sensory stimulus that evoked movement as Sherrington's reflex concept would predict. Using a spinalized dog, Brown demonstrated that rhythmic stepping and scratching could be produced without sensory input (Brown, 1914). Brown proposed that these rhythmical behaviors were the result of oscillators in the spinal cord. Largely ignored for years, Brown's idea of oscillators was an explanation that resonated with von Holst who in the 1930s was working on the rhythmic behavior of fish fins (von Holst, 1973). But the general idea of spinal oscillators or, what were to be called later, central pattern generators (CPG) would take until the work of Wilson (1961) on the wing beats of locust and the work on locomotion of vertebrates in the 1960s and 70 s before it gained wide acceptance (Grillner, 1975; Pearson \& Fourtner, 1975; Shik \& Orlovskii, 1965; 1966).

The building period $(1930-1965)$ was a critical time for adding to our understanding of the neuroanatomical and neurofunctional studies of the nervous system. Indeed it has been suggested that the 1930s were one of the most important periods in American neurophysiology (Kevles \& Geison, 1995). Meetings and publications of the American Physiological Society were dominated by those studying the nervous system. In 1938, the first issue of the Journal of Neurophysiology was published. In the second issue that year, Jasper and Andrews published their paper on "Brain potentials and voluntary muscle activity in man" (Jasper \& Andrews, 1938). Papers such as this were no doubt due to the development of new techniques for amplifying, displaying, and recording electrical signals from the human body without distortion. This rapid growth was due, in large part, to the infusion of money from the Rockefeller and Carnegie Foundations who were funding medical 
schools to develop the experimental basic sciences, particularly in areas such as neurophysiology (Kevles \& Geison, 1995).

One of the major findings from the foundation period related to the nature of how neural signals were communicated. Sherrington had introduced the term synapse (from the Greek, synapsis meaning junction) referring to the specialized contact zone (first described by Cajal) where the neurons communicated with one another. During the building period, the mechanism for synaptic transmission was found to be both electrical and chemical. Indeed, the brain would be found to be awash in chemicals. For example, Parkinson's disease which had been described in 1817 by James Parkinson was the first disease to be associated with a deficiency in a specific neurotransmitter (dopamine). In 1959, Carlsson who would later win the Nobel Prize (2000) for his discovery, identified dopamine as a transmitter in the brain that plays an important role in the control of movement. This discovery, like many during this period, was made possible by the development of the spectrophotoflorimeter which permitted the measurement of low levels of drugs, metabolites, and other endogenous compounds. Almost at the same time, Hornykiewicz's (Ehringer \& Hornykiewicz, 1960) postmortem exams of patients' brains found that some brains were low in dopamine, norepinephrine, and serotonin. Reviewing the patients' medical history, he found that all had Parkinson's disease thus showing PD was a disease of the brain associated with a deficiency in a specific neurotransmitter.

For motor behavior, other important discoveries during this building period included the discovery of corollary discharge or efference copy. Working on the visual behavior of the fish, Sperry found that at the same time as a motor command was sent to the eye muscles, a copy of this command also was sent to the visual cortex (Sperry, 1950). Similarly in 1950, von Holst published the same conclusions from his work on the fly (though he called it "reafference"). He also extended the idea to other neuromotor systems (i.e., locomotion, limb movements) as well as to the interaction of reafference from different sensory inputs (von Holst, 1973) This mechanism is critical for discriminating between images on the retina that change because the environment changes or the eyes move. How else could the animal know whether they were moving or the environment was moving? Finally, while Bernstein, a Russian physiologist, was "discovered" in the next period of motor control, he did his work during the building period (Bernstein, 1967). Bernstein made many contributions to our understanding of motor behavior, but at least three stand out according to Stuart (2005). The first was that movements are "structures" not chains of reflexes. In 1935, when Bernstein proposed this idea, he clearly was articulating a very different view point on movement than was being conceptualized by Sherrington and others in Europe. Second, he was a pioneer in talking about "motor coordination." To Bernstein, coordination was "overcoming" the excessive degrees of freedom found in the system. The third concept began as an engram (or movement formula) that was found in the brain and contained the entire movement process. But Bernstein saw this process a distributed system in which the higher CNS centers determine the chain of activity, but the lower levels tied the movements to the spatial coordinates, and still lower levels worked out the details (i.e., which muscles, joints, and limbs to involve). This concept was to guide the research of other Russian scientists for years and led to major advances in understanding the neural control of locomotion (Stuart, 2005)

The fourth period, the neuroscience period, begins in 1965 when Ragner Granit organized a meeting in Stockholm on "Muscular Afferents and Motor Control" (Brooks, 1986). The next several years saw more conferences organized around themes of physiology and movement. In 1969, the Society for Neuroscience was formed, and in 1970, Granit's book, The Basis of Motor Control was published, (Granit, 1970). Interestingly, the Journal of Motor Behavior also was inaugurated in 1969 at the University of Maryland where Richard Schmidt was on the faculty. While the latter emerged from the field of physical education and included many psychologists on the first editorial board, it nonetheless marks the growing body of work on motor behavior across all the fields.

During this neuroscience period, there are three research paradigms or threads: behavioral motor control, neuromotor (neurophysiological) control, and computational motor control. The first, behavioral motor control, overlaps with the motor learning area as described in the following section of this paper. It was comprised of those researchers who focused on the underlying mechanisms, but inferred these mechanisms from behavior. The second group, the neuromotor/neurophysiological control researchers, worked primarily on animals, but with increasing technological advances would move to studying the neural basis of human motor control. The computational motor control researchers used mathematical modeling techniques to uncover insights about how the brain controls and coordinates movement. In the last few years, a 
fourth paradigm has emerged. This is the study of the brain-machine interface or BMI (Donoghue, 2002; Lebedev \& Nicolelis, 2006). While the idea of an interface between the brain and a machine is an old concept, new technology has brought a renewed interest in creating neural prosthetics that may help those that are paralyzed. While such devices offer hope to those severely paralyzed, there are many scientific barriers to overcome. However, it is an exciting area with great potential.

In the last 40 years, the explosion of research in neuroscience and motor control, specifically, has been remarkable. This progress has been made, in large measure, to the breakthroughs in technology. Brain activity can now be captured by a wide array of noninvasive tools, each with its own particular strengths. Amongst these tools, is electroencephalogram (EEG) discovered in the 1920 s by a German psychiatrist, Hans Berger. EEG measures electrical activity of the brain by recording from electrodes placed on the scalp which measure voltage differences between different parts of the brain. It has high temporal resolution and the detected changes in electrical activity in the brain can be correlated with behavioral data. Positron emission tomography (PET) scanner which was developed by Michael Ter Pogossian and his colleagues in the 1950s (Rich, 1997) is another tool. By mid-1980s PET became useful for medical diagnosis providing three dimensional images or maps of dynamic human metabolism. Although PET is helpful and provides image reconstruction, the use of this technique in humans is limited because it requires the injection of radioactive material into participants. Magnetic Resonance Imaging (MRI), or also called Magnetic Resonance Tomography (MRT) or Nuclear Magnetic Resonance (NMR), is another developed technique for visualizing changes in living tissues. Although the foundations for using magnetic resonance was laid in the 1940s by Bloch and Purcell (who together won the Nobel Prize -1952) -the first clinical application of the MRI was in 1971 when the technique of functional magnetic resonance imaging (fMRI) arrived. fMRI measures signal changes in the brain that are due to changing neural activity and the brain is scanned at low spatial resolution but at a rapid rate (for a review see Rowe \& Frackowiak, 1999). From 1984 to 1987, Masao Koyanagi and Kado developed the system called magnetoencephalography (MEG) which is a totally noninvasive technique and provides good spatial resolution to capture the dynamics of cortical activation (for a review see Hamalainen et al., 1993). Recently, transcranial magnetic stimulation (TMS) a noninvasive and usually painless way to electrically stimulate specific brain regions has become one of the exciting new research tools in neuroscience and motor control (see Walsh \& Cowey, 2000).

The development of noninvasive imaging techniques has provide new insights about the motor system function and, today, the area of motor control is producing remarkable results. While the techniques we have for imaging the brain limit investigations to constrained movement situations, experimenters have combined different imaging tools (e.g. combining fMRI which has high resolution with MEG which provide better temporal resolution of the brain activity) to conduct very clever experiments that get the brain to reveal itself. Today, current textbooks of neuroscience include large sections on the brain and spinal control of movement (Bear et al., 2006; Purves, 2004). Efforts to help those with lesions, disease, and other disruptions of the brain areas controlling movement have made significant progress.

\section{Motor Learning}

The study of human motor learning focuses on how humans learn motor skills. Motor behavior, in general, refers to all actions that might be performed including reflexive behavior and simple movements such as a wiggle of the finger or the nod of the head. Motor skill is a special class of motor behaviors. These are task-specific motor behaviors that are achieved with certainty and efficiency (Schmidt, 1991). Motor skills, then, are not random motor behaviors; but are those that are planned, carried out with considerable consistently, and achieved with a measure of efficiency. Handwriting, sport skills, and buttoning a coat are all examples of motor skills. Motor skills are not innate, but must be acquired; hence, the study of motor learning is the study of how motor skillfulness is achieved.

Adams (1987) divided the history of motor learning into three periods: the early $(1880-1940)$; the middle (1940-1970) and, the present (1970 to present) and more recent reviews have followed his lead (Thomas, 2006). We agree with the designation of the period's dates, but prefer to name these periods so as to be more descriptive of the research characterizing that period. For Adams' early period, the term "learning principles" period would seem to capture the essence of the work during this time frame. The second period, we have named the "motor performance" period. The last period, referred to as the present period by Adams, might have been appropriate in 1987 when Adams wrote his paper, but today this period which is now 
36 years long seems inadequate to capture the considerable progress that has been made during this time. Thus, we expand and elaborate on this period.

The learning principles period (1880-1940) probably began earlier than 1880 when an astronomer named Bessel in the early 1800s (as cited by Welford, 1968) wondered about the differences among his co-workers in measuring the transit times of the stars' movement. While these measurements were not motor skills, Bessel's notion that there were different skill levels among his colleagues and his interest in the reasons why these differences existed may be seen as a forerunner of the studies which characterize the early period of motor learning. Indeed much of the early research was conducted by scientists in the nascent field of psychology and focused on: a) the practical application of motor skill research to the work place, and/or b) in using motor skills to understand learning per se. Researchers in the early period of motor learning began their work by studying relatively "simple" skills that were reasonably easy to measure. For example, they examined the learning of sending and receiving Morse code (Bryan \& Harter, 1897; 1899) and the acquisition and retention of typing (e.g. (Bean, 1912; Book, 1925; Towne, 1922). These studies asked good questions and the subject's motor performance was carefully observed. In fact, looking back at this period, a number of major concepts emerged that would influence the study of motor learning to the present day. These include: 1) the difference between learning and performance (Tolman, 1932); 2) the notion of movement memory (Hollingworth, 1909; Swift, 1910); 3) the idea that learning could be transferred (Judd, 1908; McGeogh, 1931; Thorndike \& Woodworth, 1901); and, 4) important concepts about practice and feedback such as knowledge of results, the amount of time for practice (massed or distributed), readiness, and repetition (Thorndike, 1927; Trowbridge \& Cason, 1932).

Looking back at this early period we also see the perennial issue of "nature vs. nurture" influencing the researchers' thinking on motor learning. Can anyone learn any skill (i.e., nurture or environment being the most important determinant)? Or are individuals born with the ability to learn skills easier (i.e., nature or heredity being the most important determinant)? This is an issue that, as we will see, confronts those studying motor development. And it is an issue that is still discussed to varying extents in each field today. The manner in which this issue was cast in the early 1900 s concerned how to explain the performance and learning differences observed between individuals. One group of scientists believed that our abilities were inherited while others argued that skills were learned.

The motor performance period (1940-1970) begins with the Second World War when there was considerable interest in issues related to combat performance including the identification of individuals best suited for training as pilots and gunners as well as issues of how to train pilots, design equipment, and other aspects of what was to become an area called human factors or ergonomics. It also was an important time for the development of ideas about individual differences in motor skill learning and performance (Fleishman, 1954).This period began with a flurry of research and interest in motor skills and ends with a "whimper" near the end of the 1960s when the psychologists studying motor learning declared the area dead (Bilodeau, 1966).

The motor performance period, however, is important for the emergence of two new theories: Hull's theory (Hull, 1943) and cybernetic theory (Wiener, 1948). While behaviorism actually began in the late 1910s with the emergence of the work of Watson (1914), it was not until the publication of Hull's book, Principles of Behavior in 1943, that behaviorism was to significantly affect motor skill research. Although two other behaviorists, Guthrie (1935) and Tolman (1932), both studied motor skills, it was Hull's theory that seemed to spur the greatest amount of research. Hull's theory was a general theory of learning; his predictions about the inhibition of responses seemed to have particular relevance to learning movements. While Hull's theory was eventually proven wrong, it did result in considerable research on whether practice sessions should be massed or distributed (Adams, 1987).

The cybernetics theory or information processing theory was developed during the 1940s by a group of scientists concerned with communications. This was a theory that sought to explain how information was transmitted from one place to another such as by telephone wire (Shannon \& Weaver, 1949; Wiener, 1948). From this work, they theorized that such communication systems had limited channel capacity (or, what today would be called, "bandwidth"). The ideas of this theory found their way into psychology where humans, too, were viewed as "communication systems" with limited channel capacity (Broadbent, 1958; Craik, 1948; Welford, 1952). Similarly, notions in communication theory such as coding (or how information is stored) and serial and parallel processing found their way into behavioral theories. Many of these scientists working on 
communication theory also helped develop computers. Indeed, it was the computer and the model that it provided for theorizing that was to have a lasting effect on how we were to see human behavior and motor skill behavior, in particular.

Information processing theory used the computer as a model for understanding the human brain and behavior. Whereas the behaviorist's attempted to understand the lawful relationship "connecting" a stimulus (S) and response (R) (e.g. a reward might strengthen the connection), the information processing theorists inserted a computer model between the S and R. One of the first motor learning researchers in America to adopt the information processing model for motor skills was Paul Fitts. Fitts studied what became known as the speed-accuracy trade-off, latter called Fitt's law, which expressed the relationship between the length of a movement and the accuracy required as an index of difficulty (ID) or as bits of information that can be processed by humans (Fitts, 1954). A similar law was proposed to describe the relationship between the amount of time it takes a person to respond and the number of choices presented-Hick's law (Hick, 1952). Both Fitts and Hicks saw humans as "limited processors" or systems that were unable to handle all the information available at any one time. From such ideas would emerge the concept of attention or the limited capacity to process information. Finally, it is important to note that the information processing model provided a rich metaphor in the form of a computer and its programs or as it was transformed to motor behavior, the motor program (Keele, 1968 ) or, as Henry called it, the "memory drum" (Henry \& Rogers, 1960). The concept of the motor program was one in which a set of motor commands was stored in the brain. To move required that these commands be retrieved and issued to the muscles resulting in a movement sequence that "unfolded" without necessarily requiring sensory feedback from the movement.

Adams identified his third period as the 'present' period beginning in 1970 and continuing to the current time (at the writing of his paper in 1987). Today, this present period spans 36 years and seems too rich in conceptual, methodological, and empirical findings to be referred to as merely the "present" period. Indeed, examination of this period reveals that four distinct research themes run through these years. They do not split clearly along a time line; in fact, they overlap to a large measure. The four thematic periods are: a) the "motor learning theory" period (1970-1976); b) the "behavioral motor control" period (1976 to the present); and, c), the "dynamical systems" period
(1978 to the present). A fourth theme (d) emerged in the late $80 \mathrm{~s}$ in which the neural basis of learning was investigated. This "neural basis of learning" period began primarily with research on animals, but would eventually progress to work on humans, particularly in rehabilitation.

The "motor learning theory" period began with the publication of Adam's paper in 1971 on a "closed-loop theory of motor learning" (Adams, 1971). Adams' claim was that repeating a movement strengthens the memory for that movement. But a growing set of experiments demonstrated that individuals could learn under conditions of variability of practice. These findings led Schmidt to propose an alternative theory, a "schema theory of discrete motor skill learning" (Schmidt, 1975). These competing theories resulted in considerable research on motor learning through the 70s. This was also a time in which increasing emphasis was being placed on understanding motor performance without studying learning. Researchers discovered they needed to learn more about the processes underlying movement before they could understand how motor skills were acquired (Stelmach, 1976; 1978). Two paths were followed by those seeking to know more about motor performance. The first path used the information processing approach and the second path sought to relate motor behavior to the underlying neural processes. These scientists did not probe the nervous system directly, but rather worked inferentially and through conceptual models of motor behavior to build these understandings. This period might best be characterized as the "behavioral motor control" period.

Thus, in the $80 \mathrm{~s}$, the emphasis on motor performance (either from a control or information processing perspective) served to push learning issues aside. This is well illustrated in an international conference, the NATO Advance Study Institute, held in 1979 on motor learning and control where more than 40 papers were presented with almost $90 \%$ of these oriented toward motor control (Stelmach \& Requin, 1980). This conference was significant also because it was the first major conference on motor learning and control in which the dynamical systems approach was present (Kelso et al., 1980). The dynamical systems perspective was the first significant challenge to the information processing approach. At that conference and another conference on motor development a year earlier (Kugler et al., 1982), the outlines of the dynamical systems approach to motor behavior were presented. Years earlier, Bernstein (1967) had identified two major 
problems that theories of motor behavior would have to solve - the degrees of freedom problem and the problem of context-conditioned variability (for a review see Turvey et al., 1982). The information processing approach did not have a satisfactory solution to these problems, whereas the dynamical systems perspective spoke directly to these issues. From this point forward, the 'dynamical systems period' would co-exist with the 'behavioral motor control' period.

In the late 1980s, the fourth scientific theme, "the neural basis of learning," would emerges in motor learning that continues to the present day and will lead to the blurring of the lines of distinction between motor learning and motor control. This theme is exemplified in a paper that appeared in Science by Lisberger (1988) entitled, "The neural basis for learning of simple motor skills." While this work on the neural basis of motor learning was coming primarily from those working with animals (monkeys) and simple motor skills such as the vestibular-ocular reflex (VOR), it nonetheless represented the emerging interest in understanding the underlying mechanisms of motor learning. Similarly, work was emerging in the mid 1990s from the neural computational community (cf. Grossberg \& Merrill, 1992; Shadmehr \& MussaIvaldi, 1994; Todorov et al., 1997) and from the rehabilitative sciences (Kleim et al., 1998), particularly with regard to re-learning motor skills in those with stroke (Boyd \& Winstein, 2001; Cirstea et al., 2006) .

While many, if not most, researchers from kinesiology turned their attention away from motor learning, a few maintained their interest in learning issues most noticeably in the study of optimal practice conditions. In 1979, Shea and Morgan (1979) conducted a seminal study that demonstrated the benefits of a random over a blocked practice schedule. Specifically, those who practiced three different tasks in three separate blocks had better performance during the experiment but worse retention, and hence learning, than those who practiced the three tasks in a completely random order. These results occurred regardless of whether the retention trials were themselves blocked or random suggesting that this was not a consequence of the specific practice conditions. This contextual interference effect generated considerable theoretical interest and studies over the years. For example, there are two explanations of the effect; one suggests that those who practice under random conditions engage in elaboration or deeper processing of multiple memory representations which become more distinctive and more easily recalled later (Shea \&
Zimny, 1983). The other explanation suggests that those who practice under random conditions actually have to regenerate a movement plan for each trial rather than use the same one as those who do the block conditions and that the action of regenerating the entire plan is what encourages the plan to be better retrieved after retention (Lee \& Magill, 1983). The effect itself has been found to be robust under a large variety of, but not all, task settings (Hall \& Magill, 1995) and continues to generate research questions at the present time.

Motor learning also has seen a resurgence in the last decade with the study of sensorimotor adaptation. While not learning in a classic sense, sensorimotor adaptation has theoretical and practical linkages with learning. In these experimental paradigms, individuals make a series of limb movements (mostly reaching) to targets under normal environmental conditions followed by trials in which the sensorimotor relationship is distorted. These distortions can be of the visuomotor (Kagerer et al., 1997) or the gravitational field (Shadmehr \& Moussavi, 2000) in which the movement is made. The experiments are designed to probe the internal "map" or model that the brain has for making accurate limb movements in the environment. When this map is distorted, how quickly can individuals adapt and how long do they maintain the new sensorimotor map are measured? Presumably adaptation is a critical component to long-term learning (for a full discussion see Shadmehr \& Wise, 2005).

In sum, the present period began with two motor learning theories: closed-loop theory which saw motor learning as a process of error correction and detection whereby movements were made and errors were detected and corrected on the basis of previous memory traces (Adams, 1971); and, schema theory which addressed the shortcomings of the Adam's theory and hypothesized that motor learning was the process of learning rules that later would be used to generate movements (Schmidt, 1975).

During the 1970s, the information processing approach re-focused attention from learning issues to motor control issues using behavioral methodologies. About a decade later (circa 1980), the dynamical systems approach emerged as an alternative approach proposing that movements occurred in units of actions called coordinative structures and that these units emerged to perform that task at hand from the interplay between organism, task, and environment constraints (Newell, 1986). Issues of learning motor skills were only tangentially addressed within a dynamical systems perspective (Zanone \& Kelso, 1992) 
whereas we see later in this paper, dynamical systems had great appeal to those studying motor development. Today, both theories are currently used to explain motor performance and its acquisition. The end of the last century and the start of the current one also brought interest and research in the neural basis of motor learning. Research on the neural substrates of motor learning is conducted on both animals and humans. Computational neuroscience has also shown considerable interest in motor learning. Finally, motor learning has been a critical component of the work in the last decade in rehabilitation science, particularly related to stroke rehabilitation (Krakauer, 2006).

\section{Motor development}

Those who study motor control and motor learning ask questions about how motor skills are learned, controlled, and coordinated. In general, their research has focused on the mature animal or human. Their research questions are not focused on the developmental level of the performer or the past history of that individual with regard to antecedentconsequent relationships that might influence the observed behaviors. Those scientists in motor development, on the other hand, focus on questions about the development of motor skills across the lifespan. That is, they focus on how motor skill behavior changes across the lifespan including how learning, control, and coordination change with increasing experience, physiological growth, and age.

In 1989, one of us co-authored a history of motor development (Clark \& Whitall, 1989). In that paper, we divided the study of motor development into four periods determined by the dominant theoretical approach of the time. These four periods were: the precursor period (1787-1928); the maturational period (1928-1946); the normative/descriptive period (1946-1970) and the process-oriented period (1970 - to present). As in Adams' history of motor skill learning, the most recent period, which in our motor development epochs was the "process-oriented" period, is now 36 years old and again much has changed since 1989 when we described the recent research. Today, we see two of the same divisions of the present period as were seen in motor learning; that is: the information processing period (1970-1982) and the dynamical systems period (1982-2000). By the turn of the century, the enthusiasm for the dynamical systems approach had diminished, though certainly there are still studies using this approach in motor development (cf. Corbetta et al.,
2006; Corbetta \& Bojczyk, 2002; Harbourne \& Stergiou, 2003). As with the other two sub-areas of motor behavior, the distinctiveness of motor development is being blurred with the other areas. From 2000 to the present, we see a very different approach to understanding motor behavior from a developmental perspective. We have chosen to call this new period, the "developmental motor neuroscience" period. This period is characterized by the use of control models and neuroimaging techniques that have been developed by the motor control scientists. But in this case, these techniques are focused on answering questions about the developmental issues in motor behavior.

The term "motor development" probably was not used until the $20^{\text {th }}$ century. However the foundations for this area can be found in the precursor period $(1787-1928)$. In the $19^{\text {th }}$ and early $20^{\text {th }}$ century, much of science was conducted as naturalistic observations. It is not surprising then, that this first period was dominated by the 'baby biographies' where scientists described in detail the infant behaviors they observed in the first year of life. The earliest publication of a baby biography was by Tiedemann 1787 (as cited by Borstelmann, 1983). In this biography, Tiedemann described the common sequences and transitions in motor behavior of his son from birth to $2 \frac{1}{2}$ years. About a 100 years later, Preyer wrote his classic text, The Mind of the Child (first published in German in 1881-1882 Preyer, 1909a; 1909b) which was considered a great impetus to the emergence of developmental psychology (Munn, 1965). Galton (1876) also studied children during this period, but he focused on the study of twins hoping to unravel the role of nature and nurture by providing the twins with different experiences, an approach that would remain with developmental scientists to the present.

This period also saw the emergence of Darwin as a critical theorist in biological thinking about evolution and by extension, development. Darwin's ideas about the importance of the environment in shaping animals and their adaptations to their environments would play a critical role in the ideas of developmental theorists in the next century (Charlesworth, 1992; Darwin, 1859; 1871). Interestingly, Darwin, too published a baby biography (Darwin, 1877).

With the start of the $20^{\text {th }}$ century, psychology emerges and the study of children within psychology also has its beginning. We mark the onset of the maturational period (1928-1946) with the publication of Arnold Gesell's Infancy and Human Growth (1928). Gesell, along with Myrtle McGraw, would have a profound impact on motor 
development. Their careful descriptions of infant and children's motor behaviors still serve as foundations to the field of motor development today. Indeed McGraw's drawings of the infant's upright postural development still appear in current textbooks. For McGraw, these detailed descriptions were essential in her quest to understand the brain's development. Influenced by the embryologists (e.g., Coghill, 1930) and those studying the developing brain (e.g., Tilney, 1928), both Gesell and McGraw studied "motor" development as a means to an end. Both were scientists seeking to understand human behavioral development and the motor system was merely a convenient window from which to view this development. While most of their work was descriptive in nature, they both used the experimental co-twin method. The most famous of these studies was McGraw's experiment with twins, Johnny and Jimmy. This "experiment" was designed to determine if the twins' behaviors were determined by nature (neuromaturation) or nurture (learning). The early phylogenetic (or what some would call species-specific) behaviors such as sitting and walking tended to appear at the same time in both the trained (Johnny) and untrained twin (Jimmy); however, those more ontogenetic behaviors (those unique to a culture or an individual), such as roller skating, favored Johnny. This was taken as strong support for a neuromaturational position. Years later McGraw filmed Johnny and Jimmy when they were in their twenties performing a variety of motor skills. Now young men, the twins showed distinctive differences in their movements - with Johnny demonstrating much better performance than his previously untrained brother (Clark, 1975). Despite writings by both Gesell and McGraw that suggest a more complex vision of development than simply "maturation," many today still see "motor development" as maturationally driven and these two scientists as strict maturationalists.

The normative/descriptive period (1946-1970) began following the end of World War II. Although it was not a period marked by extensive research productivity in motor development, it was, nonetheless, critical for the field. During the 1950s and 1960s, considerable research focused on children's physical growth and fitness (Clarke \& Harrison, 1962; Rarick \& Thompson, 1956). World War II had revealed that military soldiers were not "physically fit" for military service. Research on children following the war indicated that they too were not as capable of performing motor tasks that required strength, flexibility, and cardiovascular endurance. The national concern was sufficient to motivate then U.S. President Dwight D.
Eisenhower in 1956 to establish the President's Council on Youth Fitness which evolved into the current President's Council on Physical Fitness and Sports. In 1958, the American Association for Health, Physical Education, and Recreation (AAHPER) published the first version of their youth fitness test. This test along with many others that were developed during the 1950s and 1960s saw an explosion of testing children's physical capabilities which not only included strength and endurance measures such as sit-ups, but also included motor skills such as throwing, running, and jumping. Across all these test batteries, the children's motor performance was measured as a "product" of their movement (e.g., how far a child could jump or throw). But these product measures did not reflect "how" (i.e., the process) the child moved to create the product. As a result, scientists at the University of Wisconsin began an important research program in which they described in careful biomechanical detail the movement patterns of children as they performed these skills (Hellebrandt et al., 1961). This tradition of carefully documenting children's movement patterns across development would continue into the next decades with the work of Lolas Halverson and Mary Ann Roberton (cf. Roberton \& Halverson, 1988).

The 1960s also saw the emergence of a theoretical framework that had perceptual-motor development at the center of its explanation for learning disabilities (cf. Kephart, 1960). While those in physical education were studying the sportrelated gross motor performance characteristics of young children, a group of psychologists were interested in a different kind of motor performance. They were particularly concerned with how perceptual-motor relationships developed in children, with special attention to those children who could not perform certain types of motor tasks, including visuomotor coordination tasks, balance tasks, and spatial-motor tasks. Since children with learning difficulties appeared to have perceptual problems (i.e., difficulties in reading text or sounding out words), some thought that training on perceptual or perceptual-motor tasks would remediate these difficulties (Ayres, 1963). Interestingly, these psychologists presaged the next period of motor development research.

In 1989, we defined the process-oriented period as a time when the research focus was on the underlying processes of motor development. Today in 2006, it is now clear that the last three decades of the $20^{\text {th }}$ century actually saw two distinct periods: the information processing period (19701982) and the dynamical systems period (19822000). Unlike the same era in motor learning where

Brazilian Journal of Motor Behavior, 2006, Vol. 1, No. 1, 1-19 
these two research approaches co-existed, motor development in the 1980 s saw almost a total bifurcation to the dynamical systems approach, at least within the field of kinesiology.

The publication of Mechanisms of Motor Skill Development (Connolly, 1970) marks the beginning of the information processing period. Connolly and the other contributors to this book sought to explain the performance and development of motor skills in infants and children with processes such as memory, attention, and response selection that were modeled after the processes of a computer. The computer with its input (i.e., sensors), central processor (i.e., perceptual processing, response selection, response programming, attention, and memory) and output (i.e., muscles) had been proposed earlier as a possible model for the brain's activity (Craik, 1948). Unlike McGraw and Gesell in the maturational period who focused on understanding "development" as a process, the researchers during the information processing period sought to understand these hypothetical processes that would explain development. Although the research from this perspective on adult motor performance is extensive, only a few of these processes were studied in children. Memory (cf. Thomas, 1980), response processes (e.g., Clark, 1982; Hay, 1979), and schema development (e.g., Kelso \& Norman, 1978) were amongst those that demonstrated that young children were qualitatively different from adults in how they processed "information." Interestingly, the information processing approach did not spur much research interest in infants, although research on aging from this perspective was evident (e.g., Simon \& Pouraghabagher, 1978)

While many motor development researchers embraced the information processing approach, there were many who felt its level of explanation was insufficient to capture the developing movement patterns that were observed from infancy to later childhood. Indeed the body seemed to be disembodied from the computer/brain. In 1980, a new and quite radical conceptualization of motor behavior emerged. In 1982 Kugler, Kelso, and Turvey published a paper on developing systems that extended on their earlier paper in which they laid out a new approach to motor control (Kelso et al., 1980; Kugler et al., 1982). This new approach characterizes the research on motor development in the last period of the $20^{\text {th }}$ century: the dynamical systems period (19822000). Borrowing from the fields of nonlinear systems, chaos theory, dynamical systems, thermodynamics, and other fields outside motor behavior and physiology that were challenging the orthodoxy of "normal" science during the $20^{\text {th }}$ century, Kugler, Kelso, and Turvey and their many colleagues offered a new theoretical framework for studying motor coordination and control. Following many of the scientific arguments of Bernstein (1967; Turvey et al., 1982), they argued that movements were not controlled by a "motor program" but rather emerged from the selforganizing processes of a system that sought stability. Movement patterns were dynamic, constrained solutions to the 'task at hand' (cf. Jirsa \& Kelso, 2004; Kelso, 1995).

These conceptualizations of motor behavior led to a profoundly different type of research in motor development. The transformational work of Esther Thelen would act as a beacon to those who had been seeking a new theoretical framework to capture the rich and complex changes that were observed in movement across the lifespan. One experiment by Thelen, in particular, was critical to the development of the dynamical systems perspective in motor development. For decades, infant reflexes were understood to disappear with the maturation of the cortex which would "inhibit" the reflexes so that voluntary behaviors could emerge. For example, the step reflex in infants typically disappears around four months of age, presumably when the cortex had developed the necessary inhibitory connections. But Thelen had another explanation. Just about that same age, infants gain weight, particularly in their legs. Perhaps, Thelen suggested, the infants no longer exhibited stepping because the legs were too heavy to lift. In two experiments, one making infants' legs heavier and the other lighting them (by submerging them in water), Thelen and her colleagues were able to demonstrate the appearance and disappearance of the step reflex by manipulating the weight of the leg - all without invoking a maturing cerebral cortex (Thelen et al., 1984).

For the next twenty years, the dynamical systems perspective would be the dominant theoretical paradigm for those studying infants and young children. Most of the research during this period focused on locomotor skills in infants (e.g., Clark et al., 1988; Clark \& Phillips, 1993; Thelen et al., 1987; Thelen \& Ulrich, 1991) and young children (e.g., Getchell \& Roberton, 1989) with some exceptions, such as the work on infant reaching (e.g., Thelen et al., 1993).

By the end of the century, the daunting task of mathematically modeling these developing motor behaviors plus the lack of explicit predictions about future performance found motor development scientists seeking other approaches. Thelen, herself, had moved from "motor" development to 
using the approach to explain cognitive development (Thelen \& Smith, 1994) and such cognitive processes as habituation (Schöner \& Thelen, 2006). As a prolific writer and critical leader full of innovative ideas and experiments derived from the dynamic systems approach, Thelen's untimely death in 2004 surely played a role in the diminished impact of the dynamical systems approach in motor development.

Today, motor development is entering a new period which we have called the developmental motor neuroscience period. Since the period is only six years old, it may not eventually qualify as a distinctive period. But in a recent paper given at a national conference, Clark (2006) proposed this period and argued that two trends have converged to create this scientific period in motor development. First, the technological advances in non-invasive methods for investigating brain function have resulted in an explosion of research on brain function. Initially, conducted on adults, these techniques are quickly being used to understand children's brain function (Wallace et al., 2006) and their disorders (Frith, 2006). Interestingly, the Wallace study explored the differences and similarities between the brains of twins hoping to untangle brain morphology that was genetically determined compare to experiencedriven brain development. Although little imaging research has been done with children and motor behavior, there are a few studies that offer a glimpse of what might be possible (Fietzek et al., 2000; Thomas et al., 2004), although most work to date has been conducted on children with some type of disorder (mostly ADHD). The second trend that has yet to be realized in motor development is the use of computational modeling which combines behavioral, imaging, and computational approaches to understanding motor behavior. This has been used extensively in visuomotor tasks in adults (Contreras-Vidal \& Kerick, 2004) and we are now exploring this in children.

The study of motor development began at the start of the $20^{\text {th }}$ century with descriptions of infants' movements. Throughout its history, description remained an important scientific tradition. From observing and reporting to detailed cinematographic analyses, how infants and children's patterns of coordination changed across developmental time has been well chronicled. Late in the last century, research questions changed from what changed to why these changes occurred. Two scientific traditions, information processing and dynamical systems, have had a significant influence on answering these questions about why these changes. Today, the question that drove McGraw in the 1930s is now being addressed: that is, how are changes in the developing brain affecting the motor behavior we observe? But today, our question is also reversed: how does our motor behavior affect the developing brain? Nature and nurture are not mutually exclusive explanations, but rather are transactional - with each influencing the other. The current period of developmental motor neuroscience research may well take us closer to answering these questions.

\section{Where are we today?}

Scientific study begins with the description of a phenomenon and progresses to explanation. As we have described in the previous sections, the study of motor development, learning, and control began with careful observation of skill learning, infants developing, and the physiological basis of movements. Except for motor control, these subareas arose from applied questions that asked practical need-to-know questions in the work place, the home, or in physical education and coaching. For example, how can I teach somehow to perform this motor skill? Or when will my baby begin to walk? As these scientific areas developed, the focus of research changed to more fundamental scientific inquiry that examined the mechanisms of control, learning, and development. By the late $20^{\text {th }}$ century, researchers realized that to understand motor skill acquisition and development, they needed an adequate characterization and understanding of the structural and functional properties of motor control. Indeed to answer the challenging motor behavior questions today, knowledge from all three sub-areas of motor behavior are needed.

So why is it that these three areas did not converge sooner? Perhaps it was the development of motor control that limited this convergence. Certainly, an understanding of the underlying fundamental neuromotor mechanisms is essential to understanding the learning and development of motor skills. Research in motor control awaited the development of technologies such as computers and electrophysiological recordings (Spirduso, 1981). Progress has been slow. But clearly with each technological advance, researchers have gone deeper into unraveling the complexities of human motor behavior. But while new technologies opened a window to viewing the physiological processes within the human body, movement scientists also needed technological advances to measure the movement itself. If we are to understand the brain-behavior relationship, technologies are needed not only to measure the brain's activities, but also to measure the behavior 
(i.e., the movement). While scientists in the 1930 s such as McGraw had remarkable films of Johnny and Jimmy as they took their first steps, these films could only be qualitatively studied. It would take another 30 or more years before scientists could derive the kinematic and kinetic descriptions of these movements and another 30 or so years before these analyses were done quickly and simultaneously with other physiological measures such as EMG. Today, experiments can be conducted and data analyzed in about one quarter of the time that they took in the 1970s. Accuracy and sampling rates have increased dramatically. New technologies such as virtual realities that permit the manipulation of sensory environments and nano-sensors that measure real-time, sixdimensional finger tip pressures clearly will take us deeper into the neuromuscular system. A final point to add about the delay in the three areas converging should be made. Recall that motor learning and motor development research has in large measure been work done on humans. This was not true for motor control. This area began in physiology and its research was conducted primarily on animals. It was not until recently that motor control scientists turned their attention to humans (Matthews, 2004). When all three areas focused on humans, the convergence occurred more easily.

In the United States, the 1990s were designated the "decade of the brain." The federal government increased funding for brain research. Another major initiative was the human genome project. Both of these national initiatives have had profound effects on the techniques, equipment, and knowledge that have been created in the last years of the $20^{\text {th }}$ century. Technological and computational neuroscience procedures dramatically expanded our understanding of the nature of the brain and behavior. Researchers have combined behavioral data with brain images providing new descriptive and correlative data about motor actions and neuronal activity and connectivity. Techniques such as, electroencephalography (EEG), magnetoencephalography (MEG), functional magnetic resonance imaging (fMRI) and transcranial magnetic stimulation (TMS) have enhanced the level of analysis and understanding of the processes between the neural machinery and human motor behavior. Human neuroimaging have shown, for example, that the areas associated with action are also active during imitation and observation (Fadiga et al., 1995; Grezes et al., 2001).

Advances have also been made in the mathematical and computational modeling of motor behavior (Kiemel et al., 2002; Oztop et al., 2006; e.g., Peterka \& Loughlin, 2004; Shadmehr \& Wise, 2005). This effort has provided for the development of hypotheses that can be tested using these models. Scientifically, models are not proven true or false, but rather are judged based on whether they are useful or not. Clearly, there are a number of models available that have been shown to be useful. For example, coordination of grip and load finger forces have been understood as a computational model based on forward and inverse models that predict arm reaching, trajectories and grip forces and recently, brain areas of activation (Kawato, 1999). Similarly, computational models of the brain's neural networks have been used to explain the visuomotor adaptations that are made when the relationship between vision and arm movements are distorted (Wentrup-Grosse \& Contreras-Vidal , in press; Shadmehr \& Wise, 2005).

From the beginning of the $20^{\text {th }}$ century, scientists have been captivated by the question of how heredity plays a role in our development and abilities. In the 1930s, the nature vs heredity debate was at its pinnacle. But very quickly scientists realized that it was not one or the other, but the interaction of an individual's heredity with his or her environment. Throughout the $20^{\text {th }}$ century, experiments were primarily correlational (though not causal in their inference) or anecdotal. But the $21^{\text {st }}$ century is re-casting this question as scientists are mapping the human genome. Questions about the interaction of heredity and environment, though no less complex as they were before, may see some breakthroughs in this century as gene markers are identified and gene expression is mapped with developmental and experiential characteristics of individuals. Recent reviews such as the one on genes in child psychology and psychiatry (Plomin, 2005) reveal the extent to which such questions are being asked and research programs are being outlined. Indeed the human gene map for performance and health-related fitness phenotypes is updated every year (Rankinen et al., 2006) and since 2000 when this map was introduced, it has grown in size and complexity. At end of this century, our understanding of the role of heredity and environment in human motor control, learning, and development will certainly be far advanced from where we are today. For those with movement disorders, this type of research holds great hope.

Finally, motor behavior will be enriched by a broad, flexible, integrated, and multidisciplinary perspective. Dialogues and collaborated work with scientists from different areas such as biomedical science, bioengineering, biophysics, mathematics, physics, and human development, for example, are 
critical for motor behaviors scientists interested in advancing our knowledge about motor learning, control, and development.

\section{Questions for future research in motor behavior}

As look back over the last century and look to the future in the $21^{\text {st }}$ century, we see many questions that will face future scientists in motor behavior. While the list is just a start, we would suggest the following as worthy quests for future motor behavior scientists.

- How can neuroimaging techniques be better combined with behavioral data to explain human movement coordination and control?

- What mathematical and computational models will guide new experiments, provide better simulations, and increase our understanding of motor behavior?

- What is the impact of early motor experience on gene expression and subsequent motor behavior?

- Are there genetic markers for movement disorders?

- Are there genetic markers for identifying certain kinds of specific motor skillfulness, such as that seen in music, art, sports, craftsmanship, surgeons, crane operators, race car drivers, etc.?

- What are effective strategies for improving an individual's ability to acquire new skills or to re-acquire skills after injury and/or disease?

- How the principles of human motor behavior can be applied to create more adaptive robots and prostheses?

\section{The Future}

As the $21^{\text {st }}$ century begins, motor behavior and its three sub-areas are flourishing. Born, essentially, at the start of the $20^{\text {th }}$ century, motor control, learning, and development now have scientific legacies that are over a hundred years old. Each area has built a scientific foundation of substantive magnitude. Originally emerging in divergent scholarly traditions (i.e., physiology, psychology, physical education), these three subareas are now converging as one large field of motor behavior. The trend to converge began in the 1980 s for behavioral motor control and motor development when both areas employed the same theoretical frameworks (i.e., information processing and dynamical systems). As we begin the $21^{\text {st }}$ century, the sub-area, motor control, and its focus on the neural mechanisms that underlie motor performance and learning are clearly embraced by a growing number of researchers in motor learning and motor development. Motor behavior is probably the best "umbrella" term - certainly it has had wide usage. Indeed the name of the current journal, the Brazilian Journal of Motor Behavior reflects this usage. Ulrich and Reeve (2005) also strongly suggested uniting under this term. We might be ahead of our time or reflecting a parochial view, but we would suggest that the term, "motor neuroscience" be considered as a possible umbrella term as well. We acknowledge that it might not be expansive enough, as there will always be those whose main focus will remain at the behavioral level of analysis. But no matter what the term, there is much to know and much to learn in the scientific study of motor behavior; and there is a great need for the research that is done is this field.

\section{Acknowledgements}

The authors would like to thank Jill Whitall for her careful reading of this manuscript and her always insightful comments. Support for writing of this manuscript was provided by funding from NIH HD42527 (PI. Clark).

\section{References}

Adams, J. A. (1971). A closed-loop theory of motor learning. Journal of Motor Behavior, 3, 111149.

Adams, J. A. (1987). Historical review and appraisal of research on the learning, retention, and transfer of human motor skills. Psychological Bulletin, 101, 41-74.

Ayres, A. J. (1963). The development of perceptual-motor abilities: A theoretical basis for treatment of dysfunction. American Journal of Occupational Therapy, 17, 221-225.

Bean, C. H. (1912). The curve of forgetting. Archives of Psychology, 3, 1-45.

Bear, M. F., Connors, B. W., \& Paradiso, B. (2006). Neuroscience: Exploring the brain. (3 ed.) New York: Lippincott Williams \& Wilkins.

Bernstein, N. A. (1967). The coordination and regulation of movements. Oxford: Pergamon Press.

Bilodeau, E. A. (1966). Acquisition of skill. NY: Academic Press.

Book, W. F. (1925). The psychology of skill. New York: Gregg.

Borstelmann, L. J. (1983). Children before psychology. In W.Kessen (Ed.), Handbook of child psychology: Vol.1. History, theory, and methods (4 ed., pp. 1-140). New York: Wiley. 
Boyd, L. A. \& Winstein, C. J. (2001). Implicit motor-sequence learning in humans following unilateral stroke: the impact of practice and explicit knowledge. Neurosciences Letters, 298, 65-69.

Broadbent, D. E. (1958). Perception and communication. London: Pergamon Press.

Brooks, V. B. (1986). The neural basis of motor control. New York: Oxford University Press.

Brown, T. G. (1914). On the nature of the fundamental activity of the nervous centres: together with an analysis of the conditioning of rhythmic activity in progression, and a theory of evolution of function in the nervous system. Journal of Physiology, 48, 18-46.

Bryan, W. L. \& Harter, N. (1897). Studies in the physiology and psychology of the telegraphic language. Psychological Review, 4, 27-53.

Bryan, W. L. \& Harter, N. (1899). Studies on the telegraphic language. The acquisition of a hierarchy of habits. Psychological Review, 6, 345-375.

Charlesworth, W. R. (1992). Darwin and Developmental Psychology: Past and present. Developmental Psychology, 28, No. 1, 5-16.

Cirstea, C. M., Ptito, A., \& Levin, M. F. (2006). Feedback and cognition in arm motor skill reacquisition after stroke. Stroke, 37, 12371242.

Clark, J. E. (1975). Conversation with Myrtle McGraw. Personal communication.

Clark, J. E. (1982). Developmental differences in response processing. Journal of Motor Behavior, 14, 247-254.

Clark, J. E. (2006). Motor development and motor control. Paper presented at the American College of Sport Medicine, Denver, CO.

Clark, J. E. \& Phillips, S. J. (1993). A longitudinal study of intralimb coordination in the first year of independent walking: a dynamical systems analysis. Child Development, 64, 1143-1157.

Clark, J. E. \& Whitall, J. (1989). What is motor development? The lessons of history. Quest, 41, 183-202.

Clark, J. E., Whitall, J., \& Phillips, S. J. (1988). Human interlimb coordination: the first 6 months of independent walking. Developmental Psychobiology, 21, 445-456.

Clarke, H. H. \& Harrison, J. C. E. (1962). Differences in physical and motor traits between boys of advanced, normal, and retarded maturity. Research Quarterly, 33, 13-25.

Coghill, G. E. (1930). The structural basis of the integration of behavior. Proceedings of the National Academy of Sciences, 16, 637-643.
Connolly, K. J. (1970). Mechanisms of motor skill development. New York: Academic Press.

Contreras-Vidal, J. L. \& Kerick, S. E. (2004). Independent component analysis of dynamic brain responses during visuomotor adaptation. Neuroimage, 21, 936-945.

Corbetta, D. \& Bojczyk, K. E. (2002). Infants return to two-handed reaching when they are learning to walk. Journal of Motor Behavior, 34, 83-95.

Corbetta, D., Williams, J., \& Snapp-Childs, W. (2006). Plasticity in the development of handedness: evidence from normal development and early asymmetric brain injury. Developmental Psychobiology, 48, 460-471.

Craik, K. J. W. (1948). Theory of the human operator in control systems II: Man as an element in a control system. British Journal of Psychology, 38, 142-148.

Darwin, C. (1859). On the origin of species by means of natural selection. London: J.Murray.

Darwin, C. (1871). The descent of man and selection in relation to sex. London: J.Murray.

Darwin, C. (1877). Biographical sketch of the infant. Mind, 2, 285-294.

Descartes, R. (1649). Les Passions de l'Ame. Paris: Henry Le Gras.

Donoghue, J. P. (2002). Connecting cortex to machines: recent advances in brain interfaces. Nature Neuroscience, 5 Suppl., 1085-1088.

Eccles, J. C. (1959). Neuron physiology introduction. In J.Field, H. W. Magoun, \& V. E. Hall (Eds.), Handbook of Physiology: Section I: Neurophysiology (pp. 59-74). Washington, DC: American Physiological Society.

Ehringer, H. \& Hornykiewicz, O. (1960). Distribution of noradrenaline and dopamine (3hydroxytyramine) in the human brain and their behavior in diseases of the extrapyramidal system. Klinische Wochenschrift, 38, 12361239.

Fadiga, L., Fogassi, L., Pavesi, G., \& Rizzolatti, G. (1995). Motor facilitation during action observation: a magnetic stimulation study. Journal of Neurophysiology, 73, 2608-2611.

Ferrier, D. (1873). Experimental researches in cerebral physiology and pathology. West Riding Lunatics Asylum Medical Reports, 3, 30-96.

Fietzek, U. M., Heinen, F., Berweck, S., Maute, S., Hufschmidt, A., Schulte-Monting, J. et al. (2000). Development of the corticospinal system and hand motor function: central conduction times and motor performance tests. Developmental Medicine and Child Neurology, 42, 220-227. 
Fitts, P. M. (1954). The information capacity of the human motor system in controlling the amplitude of movement. Journal of Experimental Psychology, 47, 381-391.

Fleishman, E. A. (1954). Dimensional analysis of psychomotor abilities. Journal of Experimental Psychology, 48, 437-454.

Flourens, P. (1824). Recherches experimentales sur less proprietes nerveux dans les animaux vertebres. Paris.

Frith, C. D. (2006). The value of brain imaging in the study of development and its disorders. Journal of Child Psychology and Psychiatry, 47, 979-982.

Fritsch, G. \& Hitzig, E. (1870). Uber die elektriche Erregbarkeit des grusshirns. Archives of Anatomy and Physiology Wiss.Med., 37, 300332.

Galton, F. (1876). The history of twins as a criterion of the relative power of nature. Anthropological Institute Journal, 5, 391-406.

Galvani, L. (1792). De Viribus Electricitatis in Motu Musculari Commenarius. Modena: Apud Societatem Typographicum.

Gesell, A. (1928). Infancy and human growth. New York: Macmillan.

Getchell, N. \& Roberton, M. A. (1989). Whole body stiffness as a function of developmental level in children's hopping. Developmental Psychology, 25, 920-928.

Granit, R. (1970). The basis of motor control. New York: Academic Press.

Grezes, J., Fonlupt, P., Bertenthal, B.,DelonMartin, C., Segebarth, C., \& Decety, J. (2001). Does perception of biological motion rely on specific brain regions? Neuroimage, 13, 775785.

Grillner, S. (1975). Locomotion in vertebrates: Central mechanisms and reflex interaction. Physiological Reviews, 55, 247-304.

Grossberg, S. \& Merrill, J. W. (1992). A neural network model of adaptively timed reinforcement learning and hippocampal dynamics. Brain Research. Cognitive Brain Research, 1, 3-38.

Guthrie, E. R. (1935). The psychology of learning. New York: Harper.

Hall, K. G. \& Magill, R. A. (1995). Variability of practice and contextual interference in motor skill learning. Journal of Motor Behavior, 27, 299-309.

Hamalainen, M., Hari, R., Ilmoniemi, R. J., Knuutila, J., \& Lounasmaa, O. V. (1993). Magnetoencephalography - theory, instrumentation, and applications to noninvasive studies of the working human brain. Reviews of Modern Physics, 65, 413-497.

Harbourne, R. T. \& Stergiou, N. (2003). Nonlinear analysis of the development of sitting postural control. Developmental Psychobiology, 42, 368377.

Hay, L. (1979). Spatial temporal analysis of movements in children; motor programs versus feedback in the development of reaching. Journal of Motor Behavior, 11, 189-200.

Hellebrandt, F. A., Rarick, G. L., Glassow, R., \& Carns, M. L. (1961). Physiological analysis of basic motor skills. I. Growth and development of jumping. American Journal of Physical Medicine, 40, 14-25.

Henry, F. M. \& Rogers, D. E. (1960). Increased response latency for complicated movements and a "memory drum" theory of neuromotor reaction. Research Quarterly, 31, 448-458.

Hick, W. E. (1952). On the rate of gain of information. Quarterly Journal of Experimental Psychology, 4, 11-26.

Hollingworth, H. L. (1909). The inaccuracy of movement. Archives of Psychology, 13, 1-87.

Hull, C. L. (1943). Principles of behavior. New York: Appleton-Century-Crofts.

Jasper, H. H. \& Andrews, H. L. (1938). Brain potentials and voluntary muscle activity in man. Journal of Neurophysiology, 1, 87-100.

Jirsa, V. K. \& Kelso, J. A. S. (2004). Coordination dynamics: Issues and trends. New York: Springer-Verlag.

Judd, C. H. (1908). The relation of special training and general intelligence. Educational Review, $36,28-42$.

Kagerer, F. A., Contreras-Vidal, J. L., \& Stelmach, G. E. (1997). Adaptation to gradual as compared with sudden visuo-motor distortions. Experimental Brain Research, 115, 557-561.

Keele, S. W. (1968). Movement control in skilled motor performance. Psychological Bulletin, 70, 387-403.

Kelso, J. A. S. (1995). Dynamic patterns: The selforganization of brain and behavior. Cambridge: The MIT Press.

Kelso, J. A. S. \& Norman, P. E. (1978). Motor schema formation in children. Developmental Psychology, 14, 153-156.

Kelso, J. A. S., Turvey, M. T., \& Kugler, P. N. (1980). On the concept of coordinative structures as dissipative structures: I. Theoretical lines of convergence. In GE Stelmach \& J. Requin (Eds.), Tutorials in motor behavior (pp. 3-47). In NY: North Holland.

Kephart, N. (1960). The slow learner in the classroom. Columbus, OH: C.E.Merrill Books. 
Kevles, D. J. \& Geison, G. L. (1995). The experimental life sciences in the twentieth century. Osiris, 10, 97-121.

Kiemel, T., Oie, K. S., \& Jeka, J. J. (2002). Multisensory fusion and the stochastic structure of postural sway. Biological Cybernetics, 87, 262-277.

Kleim, J. A., Barbay, S., \& Nudo, R. J. (1998). Functional reorganization of the rat motor cortex following motor skill learning. Journal of Neurophysiology, 80, 3321-3325.

Krakauer, J. W. (2006). Motor learning: its relevance to stroke recovery and neurorehabilitation. Current Opinion in Neurology, 19, 84-90.

Kugler, P. N., Kelso, J. A. S., \& Turvey, M. T. (1982). On the control and co-ordination of naturally developing systems. In J.A.S.Kelso \& J. E. Clark (Eds.), The development of movement control and co-ordination (pp. 5-78). New York: John Wiley.

Lebedev, M. A. \& Nicolelis, M. A. (2006). Brainmachine interfaces: past, present and future. Trends Neuroscience, 29, 536-546.

Lee, T. D. \& Magill, R. A. (1983). The locus of contextual interference in motor skill acquisition. Journal of Experimental Psychology: Learning, Memory, and Cognition, 9, 730-746.

Liddell, E. G. T. \& Sherrington, C. S. (1925). Recruitment and some other factors of reflex inhibition. Proceedings of the Royal Society, 97B, 488-518.

Lisberger, S. G. (1988). The neural basis for learning of simple motor skills. Science., 242, 728-735.

Luciani, L. (1891). Il Cervelleto: Nuovi studi di fisiologia normale e patologica. Firenza: Le Monnier.

Matthews, P. B. C. (2004). Historical analysis of the neural control of movement from the bedrock of animal experimentation to human studies. Journal of Applied Physiology, 96, 1478-1485.

McGeogh, G. O. (1931). Whole-part problem. Psychological Bulletin, 28, 713-739.

Munn, N. L. (1965). The evolution and growth of human behavior. (2 ed.) Boston: Houghton Mifflin.

Newell, K. M. (1986). Constraints on the development of coordination. In M.G.Wade \& H. T. A. Whiting (Eds.), Motor Development in Children: Aspects of coordination and control (pp. 341-360). Boston: Martin Nijoff.
Oztop, E., Kawato, M., \& Arbib, M. (2006). Mirror neurons and imitation: a computationally guided review. Neural Networks, 19, 254-271.

Pearson, K. G. \& Fourtner, C. R. (1975). Nonspiking interneurons in walking system of the cockroach. Journal of Neurophysiology, 38, 33-52.

Peterka, R. J. \& Loughlin, P. J. (2004). Dynamic regulation of sensorimotor integration in human postural control. Journal of Neurophysiology, 91, 410-423.

Plomin, R. (2005). Finding genes in child psychology and psychiatry: when are we going to be there? Journal of Child Psychology and Psychiatry, 46, 1030-1038.

Preyer, W. (1909a). The mind of the child. Part I: The senses and the will. New York: Appleton.

Preyer, W. (1909b). The mind of the child. Part II: The development of the intellect. New York: Appleton.

Purves, D. (2004). Neuroscience. (3 ed.) Sunderland, MA: Sinauer Associates.

Rankinen, T., Bray, M. S., Hagberg, J. M., Perusse, L., Roth, S. M., Wolfarth, B. et al. (2006). The Human Gene Map for performance and healthrelated fitness phenotypes: The 2005 Update. Medicine and Science in Sport and Exercise, 38, 1863-1888.

Rarick, G. L. \& Thompson, J. J. (1956). Roentgenographic measures of leg muscle size and ankle extensor strength of 7-year-old children. Research Quarterly, 27, 321-332.

Rich, D. A. (1997). A brief history of positron emission tomography. Journal of Nuclear Medical Technology, 25, 4-11.

Roberton, M. A. \& Halverson, L. E. (1988). The development of locomotor coordination: longitudinal change and invariance. Journal of Motor Behavior, 20, 197-241.

Rosenbaum, D. A. (2005). The Cinderella of Psychology. The neglect of motor control in the science of mental life and behavior. American Psychologist, 60, 308-317.

Rowe, J. B. \& Frackowiak, R. S. (1999). The impact of brain imaging technology on our understanding of motor function and dysfunction. Current Opinion in Neurobiology, 9, 728-734.

Schmidt, R. A. (1982). Motor control and learning: A behavioral emphasis. Champaign, IL: Human Kinetics.

Schmidt, R. A. (1991). Motor learning \& performance: From principles to practice. Champaign, IL: Human Kinetics. 
Schmidt, R. A. (1975). A schema theory of discrete motor skill learning. Psychological Review, 82, 225-260.

Schöner, G. \& Thelen, E. (2006). Using dynamic field theory to rethink infant habituation. Psychological Review, 113, 273-299.

Shadmehr, R. \& Moussavi, Z. M. (2000). Spatial generalization from learning dynamics of reaching movements. Journal of Neuroscience, 20, 7807-7815.

Shadmehr, R. \& Mussa-Ivaldi, F. A. (1994). Adaptive representation of dynamics during learning of a motor task. Journal of Neuroscience, 14, 3208-3224.

Shadmehr, R. \& Wise, S. P. (2005). The computational neurobiology of reaching and pointing. Cambridge, MA: MIT Press.

Shannon, C. E. \& Weaver, W. (1949). The mathematical theory of communication. Urbana, IL: University of Illinois Press.

Shea, J. B. \& Morgan, R. L. (1979). Contextual interference effects on the acquisition, retention, and transfer of a motor skill. Journal of Experimental Psychology: Human Learning and Memory, 5, 179-187.

Shea, J. B. \& Zimny, S. L. (1983). Context effects in memory and learning in movement information. In R.A.Magill (Ed.), Memory and control of action (pp. 345-366). Amsterdam: North-Holland.

Sherrington, C. S. (1896). On reciprocal innervation of antagonistic muscles, third note. Proceedings of the Royal Society, 60, 414-417.

Sherrington, C. S. (1893). Note on the knee-jerk and the correlation of action of antagonistic muscles. Proceedings of the Royal Society, 52, 556-564.

Sherrington, C. S. (1894). On the anatomical constitution of nerves of skeletal muscles; with remarks on recurrent fibers in the ventral spinal nerve-root. Journal of Physiology, 211-258.

Sherrington, C. S. (1906). The integrative action of the nervous system. New Haven: Yale University Press.

Shik, M. L. \& Orlovskii, G. N. (1965). Coordination of the legs during dog's run. Biofizika, 10, 1037-1047.

Shik, M. L. \& Orlovskii, G. N. (1966). Control of walking and running by means of electrical stimulation of the mid-brain. Biofizika, 11, 659666.

Simon, J. R. \& Pouraghabagher, A. R. (1978). The effect of aging on the stages of processing in a choice reaction time task. Journal of Gerontology, 33, 553-561.
Sperry, R. W. (1950). Neural basis of the spontaneous optokinetic response produced by visual inversion. Journal of Comparative and Physiological Psychology, 43, 482-489.

Spirduso, W. W. (1981). The emergence of research in motor control and learning. In G.A.Brooks (Ed.), Perspectives on the academic discipline of physical education (pp. 257-272). Champaign, IL: Human Kinetics.

Stelmach, G. E. (1976). Motor control: Issues and trends. New York: Academic Press.

Stelmach, G. E. (1978). Information processing in motor control and learning. New York : Academic Press.

Stelmach, G. E. \& Requin, J. (1980). Tutorials in motor behavior. New York: North Holland.

Stuart, D. G. (2005). Integration of posture and movement: Contributions of Sherrington, Hess, and Bernstein. Human Movement Science, 24, 621-643.

Swift, E. J. (1910). Relearning a skillful act: An experimental study in neuro-muscular memory. Psychological Bulletin, 7, 17-19.

Taylor, J. (1958). Selected writings of John Hughlings Jackson. (vols. 1-2) London: Staples.

Thelen, E., Corbetta, D., Kamm, K., Spencer, J. P., Schneider, K., \& Zernicke, R. F. (1993). The transition to reaching: mapping intention and intrinsic dynamics. Child Development, 64, 1058-1098.

Thelen, E., Fisher, D. M., \& Ridley-Johnson, R. (1984). The relationship between physical growth and a newborn reflex. Infant Behavior and Development, 7, 479-493.

Thelen, E. \& Smith, L. B. , (Eds.) (1994). A dynamic systems approach to the development of cognition and action. Cambridge, MA: MIT Press.

Thelen, E. \& Ulrich, B. D. (1991). Hidden skills: a dynamic systems analysis of treadmill stepping during the first year. Monographs of the Society for Research in Child Development, 56, 1-98.

Thelen, E., Ulrich, B. D., \& Niles, D. (1987). Bilateral coordination in human infants: stepping on a split-belt treadmill. Journal of Experimental Psychology: Human Perception and Performance, 13, 405-410.

Thomas, J. R. (1980). Acquisition of motor skills: Information processing differences between children and adults. Research Quarterly for Exercise and Sport, 51, 158-173.

Thomas, J. R. (1997). Motor behavior. In J.D.Massengale \& R. A. Swanson (Eds.), The history of exercise and sport science (pp. 203292). Champaign, IL: Human Kinetics. 
Thomas, J. R. (2006). Motor behavior: From telegraph keys and twins to linear slides and stepping. Quest, 58, 112-127.

Thomas, K. M., Hunt, R. H., Vizueta, N., Sommer, T., Durston, S., Yang, Y. et al. (2004). Evidence of developmental differences in implicit sequence learning: an fMRI study of children and adults. Journal of Cognitive Neuroscience, 16, 1339-1351.

Thorndike, E. L. (1927). The law of effect. American Journal of Psychology, 39, 212-222.

Thorndike, E. L. \& Woodworth, R. S. (1901). The influence of improvement in one mental function upon the efficiency of the other functions I. Psychological Review, 8, 247-261.

Tilney, F. (1928). The brain from ape to man: A contribution to the study of the evolution and development of the human brain. New York: P.B. Hoeber.

Todorov, E., Shadmehr, R., \& Bizzi, E. (1997). Augmented feedback presented in a virtual environment accelerates learning of a difficult motor task. Journal of Motor Behavior, 29, 147158.

Tolman, E. C. (1932). Purposive behavior in animals and men. New York: Century.

Towne, B. M. (1922). An individual curve of learning: A study of typewriting. Journal of Experimental Psychology, 5, 79-92.

Trowbridge, M. H. \& Cason, H. (1932). An experimental study of Thorndike's theory of learning. Journal of General Psychology, 7, 245-258.

Turvey, M. T., Fitch, H. L., \& Tuller, B. (1982). The Bernstein perspective: I. The problems of degrees of freedom and context-conditioned variability. In J.A.S.Kelso (Ed.), Human motor behavior: An introduction (pp. 239-252). Hillsdale, NJ: Lawrence Erlbaum.

Ulrich, B. D. \& Reeve, T. G. (2005). Studies in motor behavior: 75 years of research in motor development, learning, and control. Research Quarterly for Exercise and Sport, 76, S62-S70.

von Holst, E. (1973). The behavioral physiology of animals and man: Selected papers of E. von Holst. (vol. 1) Miami, FL: University of Miami Press.

Wallace, G. L., Eric Schmitt, J., Lenroot, R., Viding, E., Ordaz, S., Rosenthal, M. A. et al. (2006). A pediatric twin study of brain morphometry. Journal of Child Psychology and Psychiatry, 47, 987-993.

Walsh, V. \& Cowey, A. (2000). Transcranial magnetic stimulation and cognitive neuroscience. Nature Reviews, Neuroscience, 1 , 73-79.

Brazilian Journal of Motor Behavior, 2006, Vol. 1, No. 1, 1-19
Welford, A. T. (1952). The psychological refractory period and the timing of high-speed performance - A review and theory. British Journal of Psychology, 43, 2-19.

Welford, A. T. (1968). Fundamentals of skill. London: Methuen.

Wentrup-Grosse, M. \& Contreras-Vidal, J. L. (in press). The role of the striatum in adaptation learning: A computational model. Biological Cybernetics.

Whitall, J. (1995). The evolution of research on motor development: new approaches bringing new insights. Exercise and Sport Science Reviews, 23, 243-273.

Wiener, N. (1948). Cybernetics. New York: Wiley.

Wilson, D. M. (1961). The central nervous control of flight in a locust. Journal of Experimental Biology, 38, 471-490.

Woodworth, R. S. (1921). Psychology: A study of mental life. New York: Henry Holt and Company.

Zanone, P. G. \& Kelso, J. A. S. (1992). Learning and transfer as dynamical paradigms for behavioral change. In G.E. Stelmach \& J. Requin (Eds.), Tutorials in Motor Behavior II (pp. 563-582). Amsterdam: North Holland.

\section{Correspondence address:}

Jane E. Clark

Department of Kinesiology

University of Maryland

College Park, MD 20742-2611

e-mail: jeclark@umd.edu

Submitted: November 12, 2006. 